\title{
Posttraumatic ulnar carpal translocation type I accompanied with disruption of the lunotriquetral ligament caused by a severe radiocarpal fracture-dislocation injury type II accompanied with complete luxation of the distal radioulnar joint. What are the salvage options with its special features in indication when patients develop posttraumatic painful wrist joint osteoarthritis?
}

Ingo Schmidt ${ }^{*}$

${ }^{1}$ SRH Poliklinik Gera GmbH, Straße des Friedens 122, 07548 Gera, Germany

\begin{abstract}
Abbreviations: RCFDI: radiocarpal fracture-dislocation injury; CREF: closed reduction and external fixation; CT: computed tomography; ORIF: open reduction and internal fixation; PA: postero-anterior; PUCT: posttraumatic ulnar carpal translocation; SLL: scapholunate ligament; LTL: lunotriquetral ligament; VISI: volar intercalated segment instability; RSCL: radioscaphocapitate ligament; OA: osteoarthritis; TWF: total wrist fusion; TWA: total wrist arthroplasty
\end{abstract}

\section{Case presentation}

A 24-year-old right-handed male sustained a severe closed right radiocarpal fracture-dislocation injury (RCFDI) due to high-energy fall on his hyperextended wrist by a motorcycle accident with speed of 102,5 miles per hour. The initial radiographs showed complete dislocation of the wrist in dorsal direction accompanied with a displaced dorsal rim fracture of the articular surface of distal radius, a displaced intraarticular radial styloid fracture involving much more than one third of the articular surface of distal radius (type II), and complete luxation of distal radioulnar joint (DRUJ) in volar direction (Figure 1). Accompanying visceral, vascular or nerve injuries were not present, but closed non-displaced fractures of the left metatarsal bones II/III. First, the closed reduction and external fixation (CREF) of the wrist and DRUJ with additional radioulnar transfixation using two K-wires was performed. The postoperative computed tomography (CT) scans demonstrated complete restoration of anatomic alignment in both joints (Figure 2A). Five days after that, the swelling around the wrist had improved, and so, the open reduction and internal fixation (ORIF) of radial styloid fracture using two $3,0 \mathrm{~mm}$ cannulated headless titanium compression screws (medartis ${ }^{\circ}$, Basel/Switzerland) could be performed that was accompanied with removal of external fixation and early denervation of the wrist (Figure 2B). Intraoperatively, there was no radiocarpal re-luxation tendency in dorsal direction related to the accompanying dorsal rim fracture, and so its surgical reduction was not necessary. The right upper extremity was immobilized with a plaster splint involving the elbow and wrist joints for another five weeks. After that, the plaster splint and the two K-wires for radioulnar transfixation were removed, and the movement of the wrist was freed accompanied with pain-related gradual increase of load. The left non-displaced fractures of the metatarsal bones II/III were treated conservatively with a plaster splint for six weeks. Fourteen weeks after injury, the patient could be reemployed completely in his original occupation as a mechanic in a professional motorcycle racing team. At the 1-year follow-up, the postero-anterior (PA) and lateral radiographs showed distinctive posttraumatic ulnar carpal translocation (PUCT) of the entire carpus (type I) in comparison to the uninjured left wrist that was accompanied with marked volar angulation of the scaphoid bone in the absence of disruption of scapholunate ligament (SLL), but in the presence of disruption of the lunotriquetral ligament (LTL) with distinctive volar intercalated segment instability (VISI) (Figure 3A-B). However, the patient rated his pain in visual analogue score (scale 0-10 points) with 1 , and his function in patient-rated wrist evaluation score (scale 0-100 points) with 9. The right wrist extension-flexion motion arc and forearm supination-pronation could be restored completely in comparison to the left uninjured wrist and forearm (Figure 4A-B).

Radiocarpal dislocations with or without accompanying fractures of distal radius and/or carpus (greater arc injuries) is an uncommon injury and the prognosis remains unpredictable. It is often associated with a dorsal rim fracture of the articular surface of distal radius potentially leading to dislocation of the carpus in dorsal direction, but dislocations in volar or various directions were observed as well [1-3]. The mechanism of injury seems to be high-energy axial loading

Correspondence to: Ingo Schmidt, SRH Poliklinik Gera GmbH, Straße des Friedens 122, 07548 Gera, Germany, Tel: 00491789503035; E-mail: schmidtingo62@googlemail.com

Key words: radiocarpal fracture-dislocation injury, dorsal rim fracture distal radius, luxation distal radioulnar joint, posttraumatic ulnar carpal translocation, volar intercalated segment instability, denervation of the wrist, salvage options for posttraumatic wrist joint osteoarthritis

Received: May 02, 2017; Accepted: May 22, 2017; Published: May 25, 2017 
Schmidt I (2017) Posttraumatic ulnar carpal translocation type I accompanied with disruption of the lunotriquetral ligament caused by a severe radiocarpal fracturedislocation injury type II accompanied with complete luxation of the distal radioulnar joint. What are the salvage options with its special features in indication when patients develop posttraumatic painful wrist joint osteoarthritis?

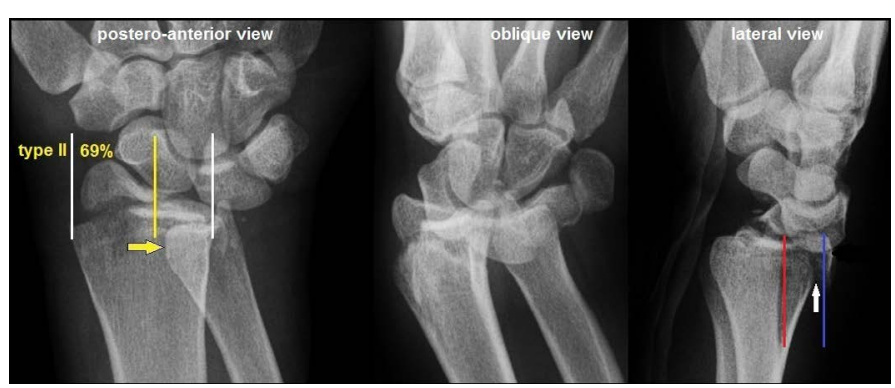

Figure 1. (Case Presentation, injury-related initial findings): Radiographs of the right wris showing RCFDI type II in dorsal direction that involves $69 \%$ of distal radius articular surface (white and yellow longitudinal lines), complete luxation of distal radioulnar joint in volar direction (yellow arrow, blue and red longitudinal lines), and a displaced dorsal rim fracture of articular surface of distal radius (white arrow).
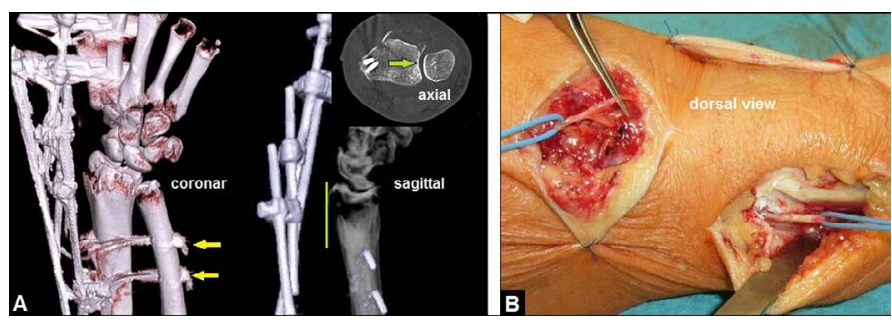

Figure 2. (Case Presentation, course): (A) Postoperative three/two/and one dimensional CT scans after CREF showing correct radiocarpal alignment, complete restoration of congruence in DRUJ (green longitudinal line and green arrow), note the radioulnar transfixation using two K-wires (yellow arrows). (B) Intraoperative clinical photograph demonstrating early denervation of the wrist during the second surgical procedure (removal of external fixation and ORIF) five days after CREF.

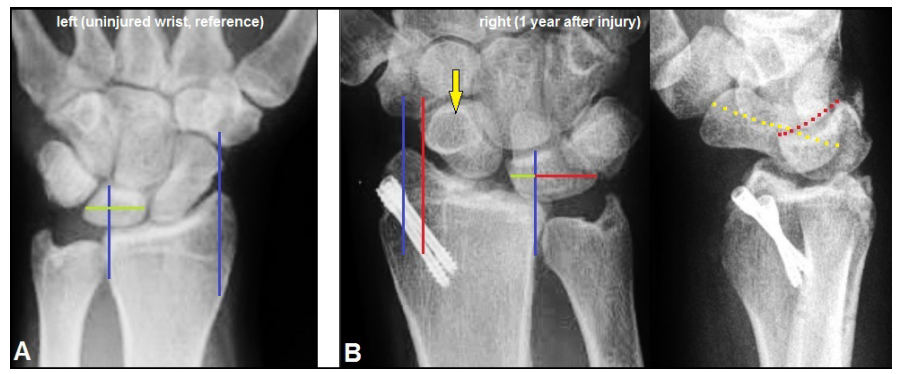

Figure 3. (Case Presentation, 1 year follow-up): (A) PA radiograph of the uninjured left wrist as reference for assessment of radiocarpal alignment, the blue longitudinal reference line through the radial styloid affected exactly the distal tubercle of scaphoid bone, a second blue longitudinal reference line was drawn which affects the sigmoid notch and crossing the lunate bone showing that more than $50 \%$ of lunate bone articulates with the lunate fossa of distal radius (green transverse line). (B) PA and lateral radiographs showing unchanged correct articulation in DRUJ, the entire carpus is translocated in ulnar direction according type I of PUCT (red longitudinal line) and less than $50 \%$ of lunate bone articulates with the lunate fossa of distal radius (green and red transverse lines), noted the positive ring sign of scaphoid bone (yellow arrow) as result of its distinctive volar angulation (yellow pointed line), also noted the VISI with distinctive volar angulation of lunate bone (red pointed line) as result of accompanied disruption of the intrinsic LTL, the two $3.0 \mathrm{~mm}$ cannulated headless compression were not removed.

combined with torsional forces to the hyperextended and pronated wrist in which the most important wrist stabilizing extrinsic ligaments are ruptured. The lesions usually are the result of falls from a height or motor-vehicle accidents mostly in young active men with age ranging from 20 to 40 years, and they are usually accompanied by visceral as well as musculoskeletal injuries, whereas low-energy injuries are very rare $[1,4-6]$. The pathology is extremely infrequent with an incidence of $0,2 \%$ of all dislocations [3,7]. Dumontier et al. [7] classified these dislocations into two types: type I includes purely ligamentous injuries with or without a small radial styloid avulsion associated with a high risk of persistent radiocarpal instability and generally poor outcomes if they present with PUCT, and type II such as in our case presentation includes a radial styloid fracture involving at least one-third of the scaphoid fossa associated with good outcomes if they can be reducted anatomically. Purely ligamentous radiocarpal dislocations may be concealed by spontaneous reduction or inadvertently reduced with gentle manipulation. Herzberg et al. [8] have been reported that the diagnosis of radiocarpal dislocations, first described in 1855 by Joseph-François Malgaigne ( $\dagger 1865$ ), was missed initially in $25 \%$ of cases. When using magnet resonance arthrography in patients with persistent posttraumatic wrist pain, a disruption of the extrinsic radioscaphocapitate ligament (RSCL) was found in $13,9 \%$ of 72 cases respectively, and a statistically significant $(\mathrm{p}<0,001)$ correlation with concomitant disruptions of the intrinsic SLL and/or LTL has been observed as well [9]. Disruptions of LTL usually show no radiographic abnormality, only in severe cases such as in our case presentation the wrist will assume a VISI with volar angulation of the lunate bone [10]. Associated nerve and/or vascular injuries are more frequent in open RCFDI [5]. If RCDFI is diagnosed, surgical intervention either with CREF or ORIF should follow as soon as possible in order to avoid secondary complications related to a compartment syndrome. When luxation tendency in dorsal direction by a displaced dorsal rim fracture is present, ORIF is the method of choice to restore stability (Figure 5A-D).

PUCT may occur as a primary traumatic ligamentous injury pattern with or without accompanying fractures or as complication after RCFDI [11]. Despite primary surgical repair of RCFDI, PUCT was observed in $23 \%$ of cases at an average follow-up of 2,8 years [12]. PUCT of the wrist without accompanying fractures of the distal radius, distal ulna, and/or carpal bones, is uncommon and was first described in 1930 by Lorenz Böhler ( $† 1973)$ [13]. PUCT is one of three major proximal carpal instabilities and the injury pattern typically results from high-energy forces through the proximal arc of the wrist $[14,15]$. The mechanism of injury is comparable to RCFDI, it appears by axial loading of the hyperextended wrist, combined with a torque and pronation of the wrist or forearm, and/or ulnar deviation on a fixed hand in which most of all volar extrinsic radiocarpal ligaments, especially the stout RSCL and the long radiolunate ligament, are ruptured [14-18]. Two types have been described by Taleisnik [15]: type I such as in our case presentation is associated with ulnar translocation of the entire carpus, and type II is associated with SLL disruption and the scaphoid bone is not involved in ulnar translocation. Due to the unfamiliarity of PUCT by treating physicians, the diagnosis is often delayed up to averaged 7,3

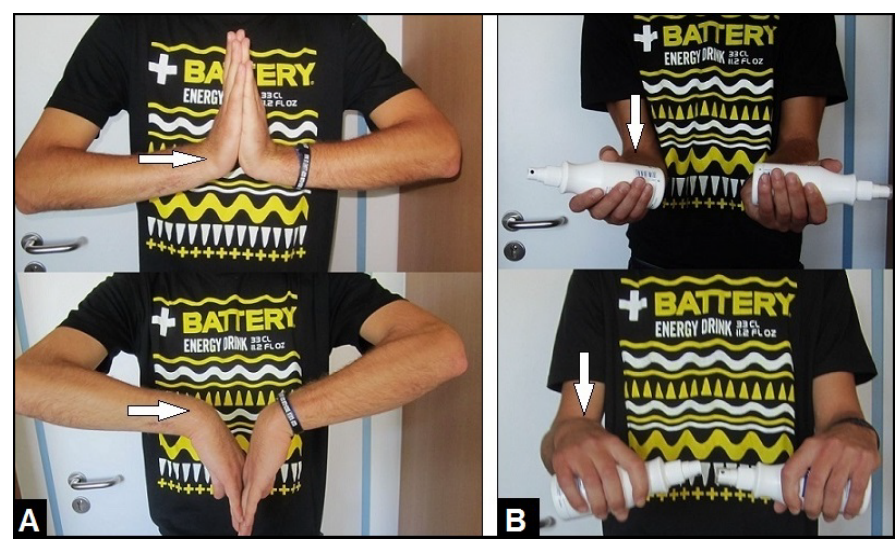

Figure 4. (Case Presentation, 1 year follow-up): (A) Clinical photographs demonstrating complete restoration of right extension-flexion motion arc (white arrow) in comparison to the left uninjured forearm. (B) Clinical photographs demonstrating complete restoration of right supination-pronation motion arc (white arrow) in comparison to the left uninjured forearm 
Schmidt I (2017) Posttraumatic ulnar carpal translocation type I accompanied with disruption of the lunotriquetral ligament caused by a severe radiocarpal fracturedislocation injury type II accompanied with complete luxation of the distal radioulnar joint. What are the salvage options with its special features in indication when patients develop posttraumatic painful wrist joint osteoarthritis?

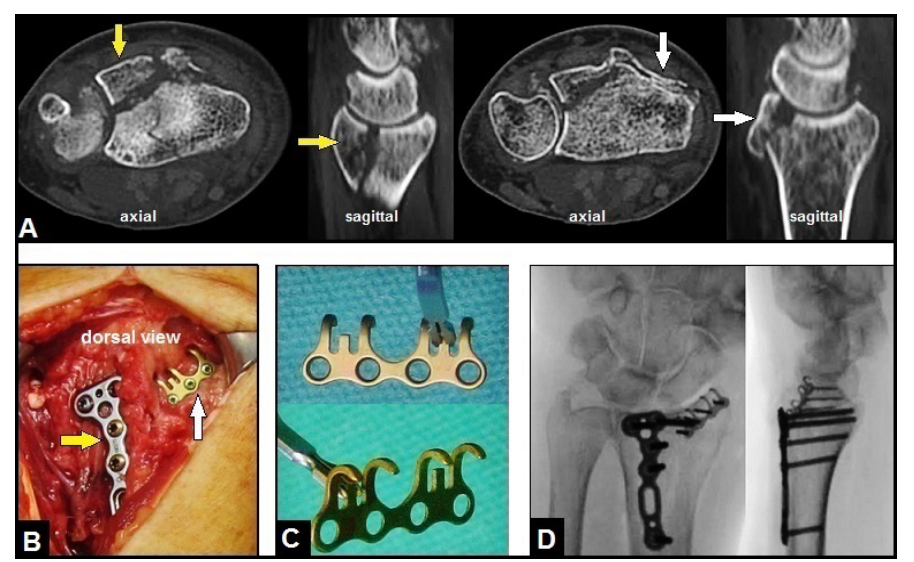

Figure 5. (Example for RCDFI accompanied with unstable dorsal rim fracture of distal radius, 56-year-old female, right wrist): (A) CT scans after primary CREF showing the ulnar-sided large dorsal intraarticular bone fragment of distal radius (yellow arrows) and the radial-sided small dorsal rim fragment (white arrows) resulting in radiocarpal instability in dorsal direction clinically. (B) Intraoperative clinical photograph demonstrating ORIF of the ulnar-sided large fragment with the use of a small $2,5 \mathrm{~mm}$ TriLock titanium dista radius plate (yellow arrow) and the radial-sided dorsal rim fracture with the use of a 1,5 $\mathrm{mm}$ titanium mini hook plate (white arrow), both plates are available by the manufacture medartis ${ }^{\circledR}$ (Basel/Switzerland). (C) Design of the $1,5 \mathrm{~mm}$ hook plate for anatomica reduction of a dorsal rim fracture. (D) Intraoperative fluoroscopy in both planes showing correct reduction of the fractures, correct positioning of both plates, and correct radiocarpal alignment.

months, and it may be present when less than $50 \%$ of the lunate bone articulates with the radius in neutral position in the PA radiograph [1921]. Nonetheless, all measurements are quite variable and should be compared to radiographs of the opposite uninjured wrist [22].

Surgical treatments for PUCT include repair of radiocarpal ligaments, tendon augmentation, radiocarpal pinning or external fixation. However, persistent or recurrent PUCT within the first postoperative year associated with patient's disability and late posttraumatic osteoarthritis have been recognized in nearly all cases, regardless of the repair technique or surgical timing, and early radiolunate fusion to prevent recurrence was recommended by Rayhack et al. [19]. However, fusions crossing the radiocarpal row cause a loss of approximately $55 \%$ of the pre-fusion flexion-extension range of motion [23]. Posttraumatic degenerative changes in the wrist have been described in majority of all cases at average follow-up's ranging from 32 months to 6,5 years, despite primary surgical restoration and/or stabilization of radiocarpal alignment [19, 24]. Irreparable cartilage damage may have occurred at the time of initial injury from compression, shear, and torsional forces. In addition, abnormal wrist mechanics in PUCT may have contributed to joint deterioration over time [24].

With the knowledge of the natural course of PUCT including its injury pattern and the poor outcome despite surgical repair, it must be emphasized with our patient that he will develop pancarpal wrist joint $\mathrm{OA}$ in the future; hence, it was and is recommended by the author to perform an early denervation of the wrist which obtains a satisfactory pain relief over a period of time [11]. This simple and fast procedure prior to a total wrist fusion (TWF) or a total wrist arthroplasty (TWA) is a suitable and reliable option. It does not decrease range of motion in the wrist, has no limit in age of patients, preserves grip strength, still allows other procedures to be performed in the future, and longterm results have been recognized a satisfactory pain relief in up to $73 \%$ of cases accompanied with a stable pain relief over time in $89 \%$ of cases at a mean follow-up period of 77 months [25-28]. When the patients develop posttraumatic prolonged painful pancarpal wrist joint OA with or without prior denervation, TWF or the motion-preserving
TWA is inevitable (Figure 6A-B) [11, 29-33]. Recent evidence suggests that patients receiving TWA significantly better rated their functional outcome than patients receiving TWF, and the complication rate of TWA with $10 \%$ does not differ significantly to those with $7 \%$ in patients undergoing a TWF $[34,35]$. TWA for treatment of posttraumatic wrist joint OA has reported to be a relative portion of $14 \%$ of all TWAs performed by surgeons who have published their experiences with this procedure [36]. Additionally, TWA is not always focused for elderly patients with low-demand claims in activities of daily living $[11,37]$. However, patients undergoing treatment with TWA must be prepared that it might end with TWF; therefore limited bone resection is a common feature of all contemporary wrist replacements $[38,39]$. For a failed TWA, TWF continues to be a salvage option, a recent study revealed that the outcome of TWF after a failed TWA is comparable to those after primary TWF [40]. The most important local contraindications for TWA are irreparable nerve palsies (Figure 7A-C), longstanding posttraumatic/postoperative wrist contracture with or without malalignment (Figure 8A-B), concomitant suspicious intraosseous lytic lesions without diagnostic clarification (Figure 8C), wrist hyperlaxity, untreated extrinsic (i.e. wrist-bridging) tendon disruptions (Figure 9A-B), unstable soft tissue with or without infection, concomitant soft tissue tumors without diagnostic clarification (Figure 10A-B), persistent posttraumatic/postoperative lymphedema and/ or chronic regional pain syndrome with stiffness of multiple joints in

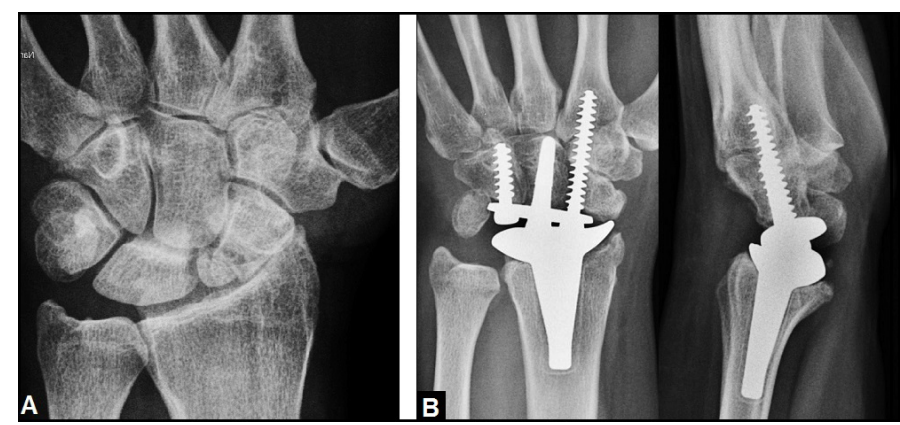

Figure 6. (Example for a typical indication of TWA in a posttraumatic condition, 57-yearold female, left wrist): (A) PA radiograph demonstrating posttraumatic wrist joint OA due to advanced stage of scaphoid non-union advanced collapse, there is no substantial bone loss nor poor bone stock. (B) PA and lateral radiographs of the same patient treated by TWA using the resurfacing RE-MOTION ${ }^{\mathrm{TM}}$ total wrist (Stryker Corporation, Kalamazoo, Michigan/USA).

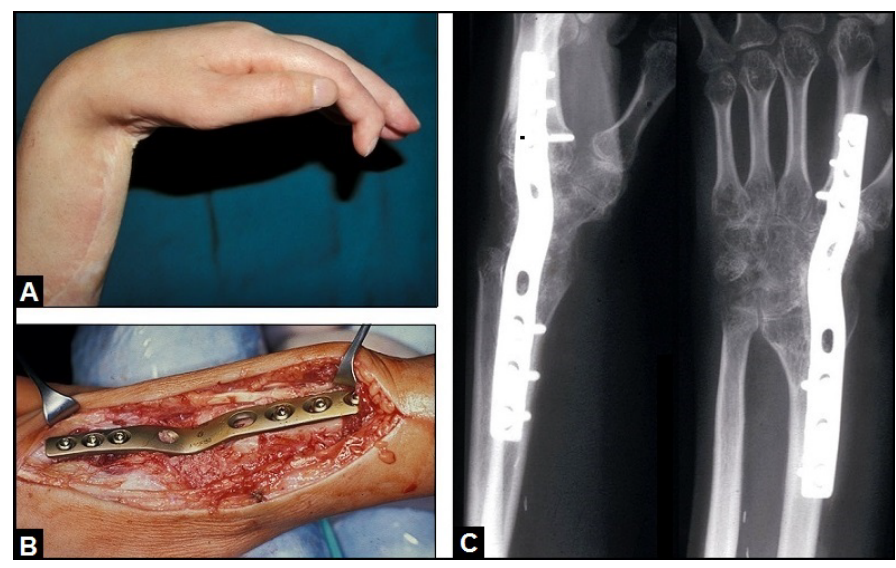

Figure 7. (Example for required TWF in a posttraumatic condition, 42-year-old female, left wrist): (A) Clinical photograph showing fixed $80^{\circ}$ flexion-contracture of the wrist caused by a longstanding irreparable radial nerve palsy due to a humeral shaft fracture. (B) Clinical photograph showing the design of the non-angle stable older generation $3,5 \mathrm{~mm} / 2,7 \mathrm{~mm}$ wrist fusion plate (formerly Synthes) that was used for TWF. (C) Postoperative PA and lateral radiographs demonstrating correct TWF. 
Schmidt I (2017) Posttraumatic ulnar carpal translocation type I accompanied with disruption of the lunotriquetral ligament caused by a severe radiocarpal fracturedislocation injury type II accompanied with complete luxation of the distal radioulnar joint. What are the salvage options with its special features in indication when patients develop posttraumatic painful wrist joint osteoarthritis?

the hand, inadequate bone stock, and distinctive substantial bone loss without a possibility for sufficient bony reconstruction (Figure 11A-F). On the other hand, TWA becomes possible if substantial carpal bone loss is reconstructable [41]. When a septic osteoarthritis is present in all joints of human, an prosthetic joint replacement is only and exclusively recommended when the infection is safely consolidated confirmed by microbiology and histology (Figure $12 \mathrm{~A}-\mathrm{D})$.
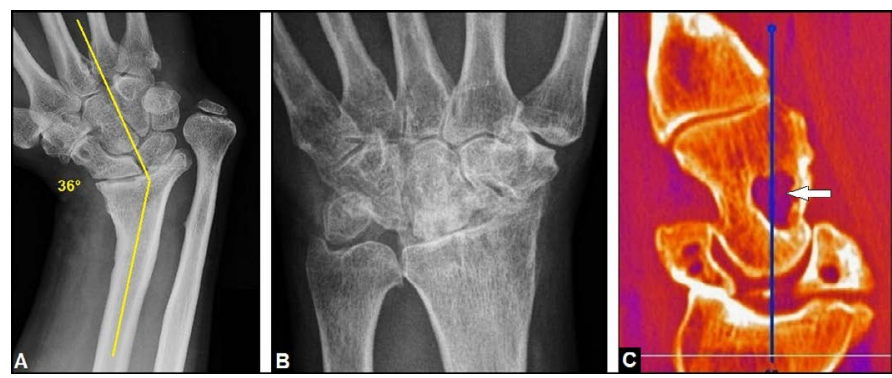

Figure 8. (Example for contraindications of TWA): (A) PA radiograph of the right wrist (57-year-old male) demonstrating severe posttraumatic malalignment in radial direction with ankylosing wrist $\mathrm{OA}$ accompanied with distinctive ulna-plus variance due to a longstanding distal radius physeal arrest, the patient sustained a distal radius fracture with age of five years that was treated conservatively, a TWA is technically not possible. (B) PA radiograph of the left wrist (38-year-old female) demonstrating longstanding ankylosing and painful wrist $\mathrm{OA}$ in neutral position secondary after scapholunate advanced collapse treated by proximal row carpectomy in another hospital, a TWA is technically possible but not recommended because an improvement of wrist motion is no longer to be expected. (C) Sagittal CT scan (62-year-old male with scapholunate advanced collapse, right wrist) demonstrating concomitant suspicious lytic lesion in the capitate bone (arrow), further diagnostic clarification is absolutely necessary.

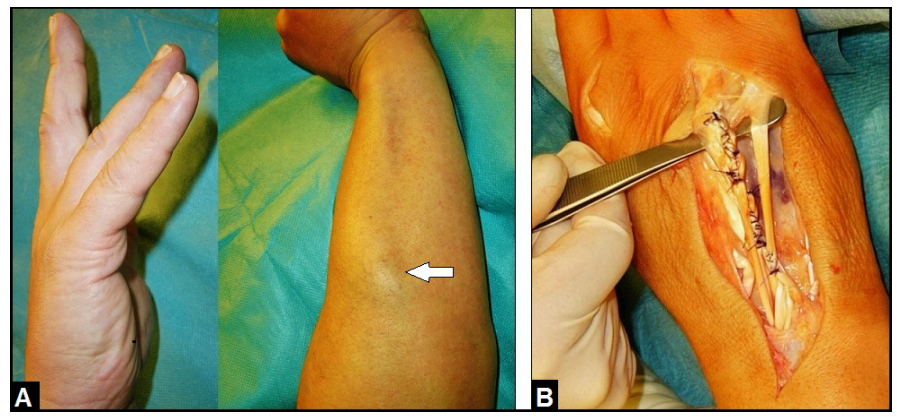

Figure 9. (Example for extrinsic tendon disruption, 53-year-old male, right forearm/wrist): (A) Clinical photographs demonstrating traumatic subcutaneous extrinsic extensor tendon disruptions for the long fingers IV and V at its musculotendinous junctions (arrow). (B) Intraoperative clinical photograph of the same patient showing tendon reconstruction by local tendon transfers.

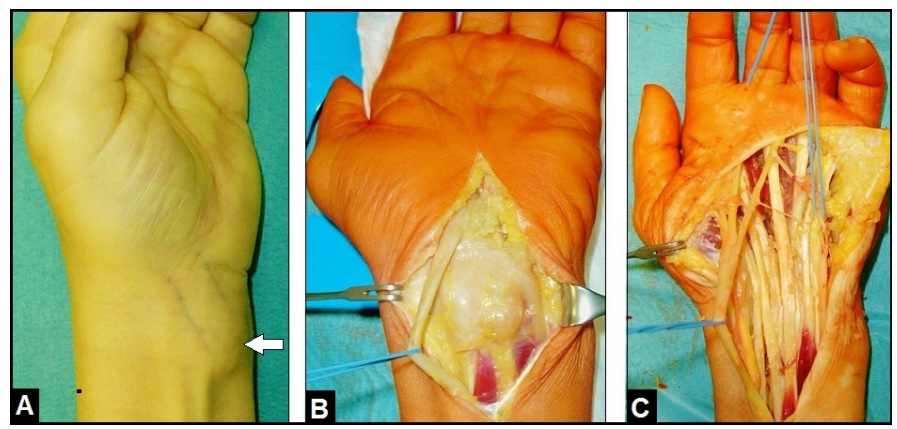

Figure 10. (Example for an unclear soft tissue tumor, 64-year-old female, left wrist): (A) Preoperative clinical photograph showing the subcutaneous soft tissue on the flexor surface (arrow). (B) Intraoperative clinical photograph showing that the tumor originates from the flexor tendon sheaths. (C) Intraoperative clinical photograph after radical flexor tendon debridement, histological examination revealed a benign giant cell tumor of the tendon sheaths.

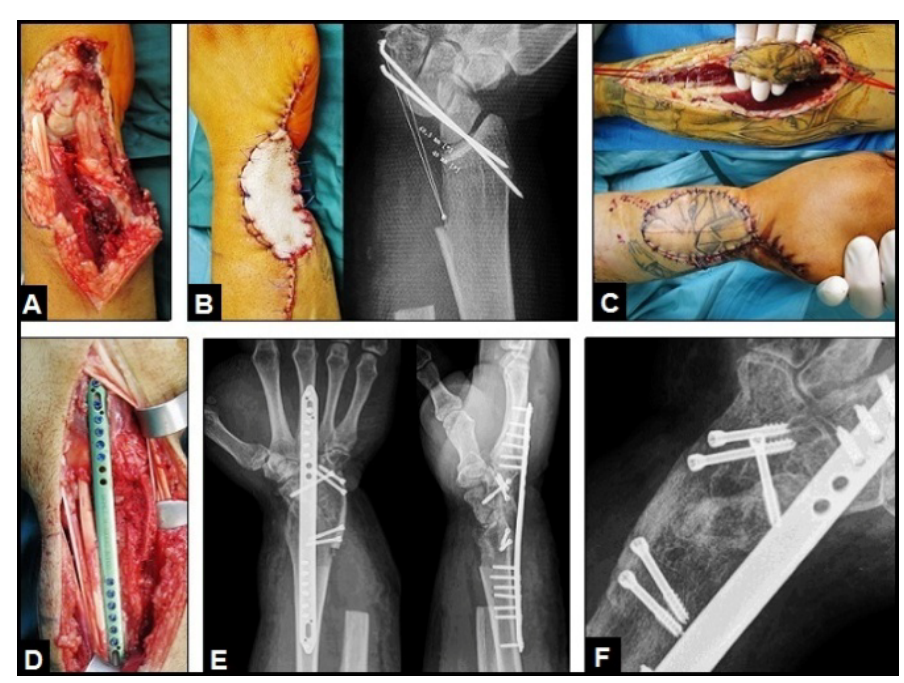

Figure 11. (Example for required TWF in a posttraumatic condition, 38-year-old male, right wrist): (A) Clinical photograph showing severe ulnar-sided crush injury after a fall in an agriculture machine. (B) Clinical photo- and PA radiograph after primary debridement demonstrating soft tissue defect temporary covered by a synthetic substitute without suction (Vacuseal, polyvinylalcohol sponge) and substantial bone loss of distal ulna, carpal bones, and sigmoid notch that does not allow a TWA, note the temporary transfixation of the "rest of wrist" using two K-wires. (C) Clinical photographs showing coverage of soft tissue defect by a distally pedicled radial artery flap. (D) Clinical photograph showing the design of the angle-stable 2,7 mm low-profile wrist spanning plate (Biomet, Warsaw, Indiana/ USA) that was used for TWF. (E) Postoperative PA and lateral radiographs demonstrating correct TWF that was additionally performed with the use of two corticocancellous iliac crest bone grafts and its additional fixation by five 3,0 $\mathrm{mm}$ cannulated headless titanium compression screws (medartis ${ }^{\circledR}$, Basel/Switzerland). (F) Oblique radiograph six months later demonstrating uneventful union of TWF.

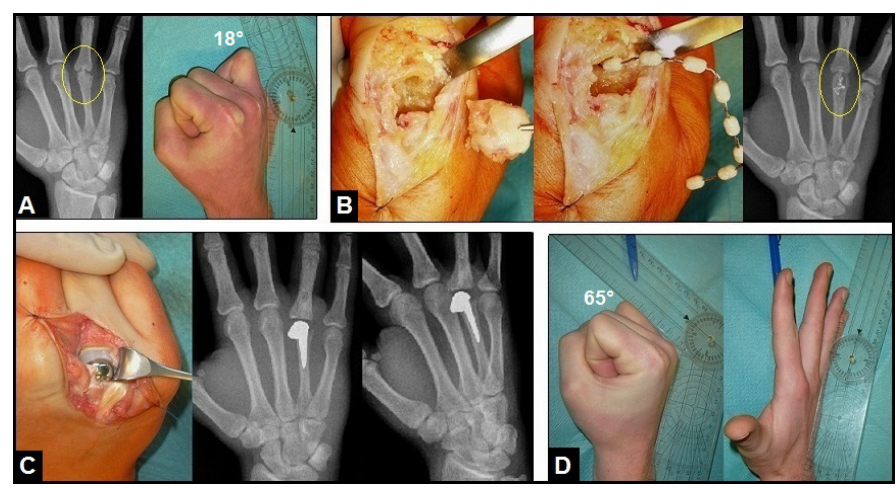

Figure 12. (Example for trauma-related septic osteoarthritis of the right metacarpophalangea joint IV after a human bite injury six weeks ago, 23-year-old male): (A) Initial PA radio- and clinical photographs showing advanced infect-related destruction of the head of metacarpal bone IV (yellow oval-circle) which led to marked loss of function in metacarpophalangeal joint IV. (B) Intra- and postoperative clinical photo- and PA radiographs demonstrating surgical management by bony debridement and incorporation of polymethyl methacrylate beads containing gentamycin (yellow oval-circle), microbiological examination confirmed bacterial load with Staphylococcus aureus. (C) Intraoperative clinical photo- and postoperative radiographs in two planes demonstrating insertion of the partially cemented unconstrained resurfacing $\mathrm{SR}^{\mathrm{TM}} \mathrm{MCP}$ prosthesis (Stryker Corporation, Kalamazoo, Michigan/USA), the septic arthritis was safely consolidated confirmed by microbiology and histology. (D) Clinical photographs at the 1-year follow-up showing marked improvement of the extension-flexion motion arc in metacarpophalangeal joint IV.

\section{Acknowledgements}

None.

\section{Declarations}

The author declares that he has none conflict of interests concerning this article. 
Schmidt I (2017) Posttraumatic ulnar carpal translocation type I accompanied with disruption of the lunotriquetral ligament caused by a severe radiocarpal fracturedislocation injury type II accompanied with complete luxation of the distal radioulnar joint. What are the salvage options with its special features in indication when patients develop posttraumatic painful wrist joint osteoarthritis?

\section{References}

1. Bilos ZJ, Pankovich AM, Yelda S (1977) Fracture-dislocation of the radiocarpal joint. J Bone Joint Surg Am 59: 198-203.[Crossref]

2. Wagner CJ (1959) Fracture-dislocations of the wrist. Clin Orthop 15: 181-196.

3. Dunn AW (1972) Fractures and dislocations of the carpus. Surg Clin North Am 52: 1513-1538.[Crossref]

4. Weiss C, Laskin RS, Spinner M (1970) Irreducible radiocarpal dislocation. A case report. J Bone Joint Surg Am 52: 562-564. [Crossref]

5. Mourikis A, Rebello G, Villafuerte J, Moneim M, Omer GE Jr, et al. (2008) Radiocarpa dislocations: review of the literature with case presentations and a proposed treatment algorithm. Orthopedics 31: 386-392.

6. Jiménez- Jiménez IJ, Caballero-Martel JR, Ojeda-Castellano J (2014) Radiocarpal dislocation after a trivial injury. Rev Esp Cir Ortop Traumatol 59: 66-68. [Crossref]

7. Dumontier C, Meyer zuReckendorf G, Sautet A, Lenoble E, et al. (2001) Radiocarpa dislocations: classification and proposal for treatment. A review of twenty-seven cases. J Bone Joint Surg Am 83: 212-218. [Crossref]

8. Herzberg G, Comtet JJ, Linscheid RL, Amadio PC, Cooney WP, et al. (1993) Perilunate dislocations and fracture-dislocations: a multicenter study. J Hand Surg Am 18: 768779. [Crossref]

9. Theumann NH, Etechami G, Duvoisin B, Wintermark M, Schnyder P, et al. (2006) Association between extrinsic and intrinsic carpal ligament injuries at MR arthrography and carpal instability at radiography: initial observations. Radiology 238: 950-957.

10. Cerezal L, de Dios Berná-Mestre J, Canga A, Llopis E, Rolon A, et al. (2012) MR and CT arthrography of the wrist. Sem Musculoskelet Radiol 16: 27-41. [Crossref]

11. Schmidt I (2017) Does Total Wrist Arthroplasty for Treatment of Posttraumatic Wris Joint Osteoarthritis in Young Patients Always Lead to Restriction of High-demand Activities of Daily Living? Case Report and Brief Review of Literature. Open Orthop J11: BSP-TOORTHJ-2017-0030

12. Yuan BJ, Dennison DG, Elhassan BT, Kakar S (2015) Outcomes after radiocarpal dislocation: a retrospective review. Hand (NY) 10: 367-373. [Crossref]

13. Böhler L (1930) Verrenkungen der Handgelenke. Acta Chir Scand 67: 154-177.

14. Linscheid RL, Dobyns JH, Beckenbaugh RD, Cooney WP 3rd, Wood MB (1983) Instability patterns of the wrist. $J$ Hand Surg Am 8: 682-686.[Crossref]

15. Taleisnik J (1988) Current concepts review. Carpal instability. J Bone Joint Surg Am 70: 1262-1268.[Crossref]

16. Bellinghausen HW, Gilula LA, Young LV, Weeks PM (1983) Post-traumatic palmar carpal subluxation. Report of two cases. J Bone Joint Surg Am 65: 998-1006. [Crossref]

17. Viegas SF, Patterson RM, Ward K (1995) Extrinsic wrist ligaments in the pathomechanics of ulnar translation instability. J Hand Surg Am 20: 312-318. [Crossref]

18. Rettig AC, Rettig LA, Jelinek JA (2010) Ulnar translocation of the wrist in a professional quarterback: a case report. Am J Sports Med 38: 608-612.[Crossref]

19. Rayhack JM, Linscheid RL, Dobyns JH, Smith JH (1987) Posttraumatic ulnar translation of the carpus. J Hand Surg Am 12: 180-189.[Crossref]

20. Stäbler A, Baumeister RG, Szeimies U, Fink U, Berger H (1994) Rotatory palmar subluxation of the lunate in post-traumatic ulnar carpal translocation. Skeletal Radiol 23: $103-106$.

21. Ross M, Di Mascio L, Peters S, Cockfield A, Taylor F, et al (2014) Defining residua radial translation of distal radius fractures: a potential cause of distal radioulnar joint instability. J Wrist Surg 3: 22-29. [Crossref]
22. Rutgers M, Jupiter J, Ring D (2009) Isolated posttraumatic ulnar translocation of the radiocarpal joint. J Hand Microsurg 1: 108-112.

23. Meyerdierks EM, Mosher JF, Werner FW (1987) Limited wrist arthrodesis: a laboratory study. J Hand Surg Am 12: 526-529.

24. Berschback JC, Kalainov DM, Husain SN, Wiedrich TA, Cohen MS, et al. (2012) Traumatic ulnar translocation of the carpus: early recognition and treatment. $J$ Hand Surg Eur Vol 37: 755-764. [Crossref]

25. Schweizer A, von Känel O, Kammer E, Meuli-Simmen C (2006) Long-term follow-up evaluation of denervation of the wrist. J Hand Surg Am 31: 559-564.[Crossref]

26. Rothe M, Rudolf KD, Partecke BD (2006) Long-term results following denervation of the wrist in patients with stages II and III SLAC-/SNAC wrist. Handchir Mikrochir Plast Chir 38: 261-266. [Crossref]

27. Hohendorff B, Mühldorfer-Fodor M, Kalb K, von Schoonhoven J, Prommersberger KJ (2012) Long-term results following denervation of the wrist. Unfallchirurg 115 343-352. [Crossref]

28. Simon E, Zemirline A, Richou J, Hu W, Le Nen D (2012) Complete wrist denervation: a retrospective study of 27 cases with a mean follow-up period of 77 months. Chir Main 31: 306-310.

29. Wei DH, Feldon P (2017) Total Wrist Arthrodesis: Indications and Clinical Outcomes. $J$ Am Acad Orthop Surg 25: 3-11.

30. Boeckstyns ME, Herzberg G, Sørensen AI, Axelsson P, Krøner K, et al. (2013) Can total wrist arthroplasty be an option in the treatment of the severely destroyed posttraumatic wrist? J Wrist Surg 2: 324-329. [Crossref]

31. Schmidt I (2014) Primary combined replacements for treatment of distal radius physeal arrest. J Wrist Surg 3: 203-205.

32. Schmidt I (2017) The Maestro ${ }^{\mathrm{TM}}$ Wrist Reconstructive System for treatment of posttraumatic wrist joint osteoarthritis after a devasting course of a distal radius fracture: Case presentation and technical note to the implant. Trauma Emerg Care 2: DOI: 10.15761/TEC.1000124 (ePub)

33. Schmidt I (2017) RE-MOTION ${ }^{\mathrm{TM}}$ Total wrist arthroplasty for treatment of advanced stage of scaphoid non-union advanced collapse. Does excision of the entire scaphoid bone prevent impingement at terminal range of radial deviation? Trauma Emerg Care 2: DOI: 10.15761/TEC.1000127 (ePub).

34. Nydick JA, Watt JF, Garcia MJ, Williams BD, Hess AV (2013) Clinical outcomes of arthrodesis and arthroplasty for the treatment of posttraumatic wrist arthritis. $J$ Hand Surg Am 38: 899-903. [Crossref]

35. Melamed E, Marascalchi B, Hinds RM, Rizzo M, Capo JT (2016) Trends in the Utilization of Total Wrist Arthroplasty versus Wrist Fusion for Treatment of Advanced Wrist Arthritis. $J$ Wrist Surg 5: 211-216. [Crossref]

36. Boeckstyns ME (2014) Wrist arthroplasty--a systematic review. Dan Med J 61: A4834.[Crossref]

37. Nicoloff M (2015) [Total wrist arthroplasty--indications and state of the art]. Z Orthop Unfall 153: 38-45.[Crossref]

38. Reigstad O, Røkkum M (2014) Wrist arthroplasty: where do we stand now? A review of historic and contemporary designs. Hand Surg 19: 311-322.

39. Adams BD, Kleinhenz BP, Guan JJ (2016) Wrist Arthrodesis for Failed Total Wrist Arthroplasty. J Hand Surg Am 41: 673-679.[Crossref]

40. Reigstad O, Holm-Glad T, Thorkildsen R, Grimsgaard C, Røkkum M (2017) Successfu conversion of wrist prosthesis to arthrodesis in 11 patients. J Hand Surg Eur Vol 42: 84-89.

41. Schmidt I (2016) An Unusual and Complicated Course of a Giant Cell Tumor of the Capitate Bone. Case Rep Orthop 2016:3705808. Epub 2016 Oct 25.[Crossref]

Copyright: $(02017$ Schmidt I. This is an open-access article distributed under the terms of the Creative Commons Attribution License, which permits unrestricted use, distribution, and reproduction in any medium, provided the original author and source are credited. 